\title{
Taxonomy of the genus Compsonannus Reuter (Heteroptera, Miridae) of the Eremian subregion
}

\author{
Rauno E. Linnavuori
}

Linnavuori, R. E. 1990: Taxonomy of the genus Compsonannus Reuter (Heteroptera, Miridae) of the Eremian subregion. - Entomol. Fennica $1: 123-128$.

The taxonomy of the genus Compsonannus Reuter of the Near East and North Africa is described. New species: Compsonannus hesione from Israel. New combination: Compsidolon maculicorne Linnavuori = Compsonannus maculicornis (Linnavuori).

Rauno E. Linnavuori, Somersoja, SF-21220 Raisio, Finland

Compsonannus is closely related to Compsidolon Reuter. It differs from that genus in the maculate 2nd antennal joint. Moreover, the body is markedly more robust, and the membrane of the elytra are densely and conspicuously mottled with fuscous. In Compsidolon the membrane is uniformly whitish or infumed with faint pale spots; only in certain species inhabiting the Canary Islands is the membrane ornamented with faint dark mottling. The vesica in Compsidolon is long and ends in a scythe-like apical part, and the gonopore is located far from the apex.

\section{Compsonannus Reuter}

Compsonannus Reuter 1902:63

Type species: $C$. puncticornis Reuter.

Color pale grayish or yellowish ochraceous, rarely (puncticornis) with reddish tinge. Elytra, sometimes also pronotum, with fuscous dotting (faint in ovatus); Membrane with distinct dense fuscous mottling, a small whitish spot at apex of cuneus. 1st antennal joint with one or two rings of blackish spots, 2nd ornamented with fuscous or blackish spots. Anterior and middle femora with abundant black mottling. Under surface, anterior margin and apex of upper surface of hind femora with \pm confluent dark mottling. Tibiae with black or fuscous spots, those on hind tibiae smaller and fainter than on the others; tibial spines delicate, pale.

Length $3.0-3.5 \mathrm{~mm}$. Body robust, parallelsided. Hair covering on upper surface dense, consisting of longish semierect yellowish or partially dark hairs and adpressed whitish pubescence. Head in frontal view nearly as high as broad or broader than high, dorsal margin of head in lateral view gradually sloping ventrad; eyes relatively small. Antennae long and slender. Rostrum long, extending at least slightly beyond hind coxae. Pronotum transverse, about $2.5 \times$ as broad as long in middle. Claws (Fig. 3a, c) slender, provided with small pulvilli.

Male genitalia: Vesica robust, provided with one or two apical processes, in the latter case the lower process coarsely dentate; in maculicornis the apex of the vesica is triangularly expanded, simple; gonopore close to apex. Other genitalia of the common type.

Distribution: Eremian, extending from North America to the Middle East.

Remarks: Wagner (1965:87-88) incorrectly recorded that the genus has no pulvilli and consequently included it in the Atomoscelis group. 
Key to the species

1. Rostrum extends to near apex of abdomen .... hesione

- Rostrum much shorter ............................................ 2

2. Upper surface with distinct reddish tinge. Scutellum fuscous with two pale spots in basal margin. Clavus, corium and cuneus with very dense, often confluent minute reddish dotting puncticornis

- Color whitish or yellowish ochraceous. Scutellum pale. Elytra with fuscous unevenly distributed dotting ..... 3

3. 2nd antennal joint about as long as basal width of pronotum longicornis

- 2nd antennal joint distinctly shorter than basal width of pronotum

4. Upper surface nearly uniformly pale, only traces of fuscous dotting seen on elytra. 3rd joint of hind tarsus shorter than 2nd. Vesica with two apical processes ....

- Scutellum, clavus and base of corium with distinct fuscous dots. 3rd joint of hind tarsus longer than 2 nd. Vesica without apical processes maculicornis

\section{C. puncticornis Reuter}

Figs. 1a-f, 3a-b.

Compsonannus puncticornis Reuter 1902:64

Compsidolon thymelaeae Wagner 1968:109-110 (Wagner 1971:95-96).

Type studied: Morocco, Tan-Tan Oued Dra, male holotype of thymelaeae, 7.V.1967, H. Eckerlein, in Mus. Hamburg.

Diagnosis: Upper surface with reddish tinge. Scutellum fuscous with two pale basal spots. Elytra with very dense minute reddish dotting.

Length $3.75 \mathrm{~mm}$. Ground color pale yellowish with reddish tinge. Head reddish ochraceous with faint reddish lateral arcs. Eyes pale gray. Antennae pale ochraceous, 1 st joint with two conspicuous dark rings, 2nd with faint reddish spots. Pronotum slightly infumed, with faint and dense, often confluent, minute brown dots. Scutellum infumed, basal margin laterally orange, disk with dense minute dark irroration. Elytra: apical margin of mesocorium with irregular transverse purplish band; clavus, corium and cuneus with dense, often confluent minute reddish brown dots, dots on cuneus red; membrane with dense fuscous mottling. Legs yellowish. Fore and middle femora with abundant dark brown mottling. Hind femora with reddish tine, anterior margin embrowned. Fore and middle tibiae with distinct, hind tibiae with very small and faint dark dots.
Body large, parallel-sided. Head $0.67 \times$ as broad as pronotum, in lateral view as high as broad, in frontal view $1.42 \times$ as broad as high; ocular index 1.87. Proportions between antennal joints 12:62:48:25, 2nd joint $1.36 \times$ as long as diatone, $0.91 \times$ as long as basal width of pronotum. Rostrum extending to apex of hind coxae. Proportions between hind tarsomeres 10:16:15.

Male genitalia in Fig. 11b.

Biology: On Thymelaea hirsuta.

Distribution: Known from Morocco, Algeria and Tunisia.

The species is very close to $C$. ovatus, but differs in the large size, very dense and \pm confluent reddish or reddish brown dotting on the upper surface and the smaller eyes.

\section{C. ovatus Wagner}

Fig. $3 \mathrm{c}-\mathrm{g}$

Compsonannus ovatus Wagner 1974a:96-98.

Type studied: Israel, Negev, ca $10 \mathrm{~km}$ East of Dimona, male holotype (immature), 15.V.1972, H. Eckerlein, in Mus. Hamburg.

Material studied: Israel: Negev, Mt. Ramon, Es Saharonim, 7 exx, 13.VII.1986; Revivim, 1 ex, 4.VI.1986, Linnavuori.

Diagnosis: Upper surface yellowish ochraceous. Fuscous dots on elytra very indistinct. 2nd antennal joint shorter than basal width of pronotum. Vesica with two apical processes.

Length 3.0-3.25 mm. Yellowish ochraceous. Eyes reddish gray. Antennae pale yellowish; 1st joint with two distinct rings of dark spots, 2nd with faint dark dots. Anterolateral corners of pronotum with dark dots. Apical margin of corium tinged with red; dark dotting on elytra often indistinct or nearly absent; membrane with distinct dense dark mottling. Fore and middle femora and the corresponding tibiae with distinct dark spots. Hind femora with slight reddish tinge, anterior margin appearing dark owing to dense fuscous mottling. Hind tibiae with very small faint dark dots.

Hair covering on upper surface yellowish. Head about $0.74 \times$ as broad as basal width of pronotum, in lateral view as high as long, in frontal view about $1.52 \times$ as broad as high; ocular index 1.60-1.78. Proportions between antennal joints 14:62:47:25, 2nd joint about $1.24 \times$ as long 
as diatone, $0.91 \times$ as long as basal width of pronotum. Rostrum extending distinctly beyond hind coxae. Pronotum about $2.52 \times$ as broad as long in middle. Proportions between hind tarsomeres 10:16:14.

Male genitalia in Fig. $11 \mathrm{~d}-\mathrm{g}$.

Biology: At lamp in desert habitats.

Distribution: The Negev desert in Israel.

\section{C. longicornis Wagner}

Figs. $1 \mathrm{~g}-\mathrm{j}, 3 \mathrm{~g}-\mathrm{i}$

\section{Compsonanmus longicornis Wagner 1971:96-98.}

Types studied: Algeria, Biskra, male holotype, 28-30.IV.1964, H. Eckerlein; the Spanish Sahara, Oued Agonidei, 1 paratype, 6.V.1942, Morales, in Mus. Hamburg.

Material studied: Israel: Negev, 'Ein Avdat, 3 exx, 29.VI.1986, Linnavuori.

Diagnosis: Upper surface whitish ochraceous with distinct dark dotting. 2nd antennal joint as long as basal width of pronotum.

Length $2.75-3.25 \mathrm{~mm}$. Whitish or yellow ochraceous. Head: frons with faint brownish lateral arcs. Eyes grayish brown. Antennae whitish, 1 st joint with incomplete narrow subapical ring or blackish spots, 2nd with several small blackish spots. Pronotum with numerous dark brown spots. Base of scutellum with middle spots formed by confluent dark brown dotting, apex ornamented with small dark brown dots. Extreme tip of clavus black; clavus, corium and cuneus with distinct unevenly distributed dark brown spots, costal margin and lateral margin of cuneus with numerous dark spots (dark dotting of elytra fainter in the holotype than in the Israeli specimen); membrane whitish with abundant dark mottling. Under surface of thorax with minute dark spots. Legs whitish. Anterior and middle femora with sparse dark brown spots. Hind femora with minute dark mottling on anterior margin. All tibiae with distinct dark brown spots.

Body elongately ovate. Head $0.72 \times$ as broad as basal width of pronotum, in lateral view about as long as high, in frontal view $1.34 \times$ as broad as high; ocular index 1.65-1.83. Proportions between antennal joints 11:58:42:26, 2nd joint about $1.38 \times$ as long as diatone, $1.0 \times$ as long as basal width of pronotum. Rostrum extending beyond hind coxae. Proportions between hind tarsomeres 9:16:14.

Male genitalia in Fig. 11h-i.

Biology: At lamp in desert habitats.

Distribution: Formerly known from the Spanish Sahara and Algeria.

\section{C. hesione sp. $\mathrm{n}$.}

Figs. 2, 3j-m

Material studied: Israel: the Negev, 'Ein 'Avdat, male holotype, $10^{7}$ paratype, 10.VIII.1986, Linnavuori, in coll. Linnavuori.

Diagnosis: Recognized by the very long rostrum, which extends to near the apex of the abdomen, and by the shape of the vesica.

Length $3.25 \mathrm{~mm}$. Pale ochraceous. Frons with faint fulvous lateral stripes. Eyes grayish brown. Antennae whitish, 1st joint with transverse subapical row of two black spots on upper surface, 2 nd with blackish dots, joints 3 and 4 slightly infumed. Calli of pronotum slightly infumed, anterolateral area of disk with fuscous dots. Base of scutellum with dark brown middle point, apical part with a few \pm distinct dark dots. Apical part of mesocorium with faint triangular orangish spot; clavus and basal part of mesocorium with dense fuscous dotting; costal margin, apicolateral angle of corium and margin of cuneus also with dark dots; membrane with dense fuscous mottling. Legs whitish. Apical parts of fore and middle femora with dark brown spots. Fore and middle tibiae with distinct black spots. Anterior margins of hind femora with dark brown spots. Hind tibiae with small dark dots.

Hair covering on upper surface pale, partially dark. Head $0.72 \times$ as broad as basal width of pronotum, in lateral view about as long as high, in frontal view $1.21-1.29 \times$ as broad as high; frons convex; ocular index 1.60-1.64. Proportions between antennal joints 13:60:45:23, 2nd joint 1.11 $\times$ as long as diatone, $0.8 \times$ as long as basal width of pronotum. Rostrum very long, extending to near apex of abdomen. Pronotum $2.8 \times$ as broad as long in middle. Apical part of scutellum convex. Proportions between hind tarsomeres 10:16:16.

Male genitalia in Fig. $3 \mathrm{k}-\mathrm{m}$.

Etymology: Greek mythology, Hesione, daughter of Laomedon, king of Troy. 


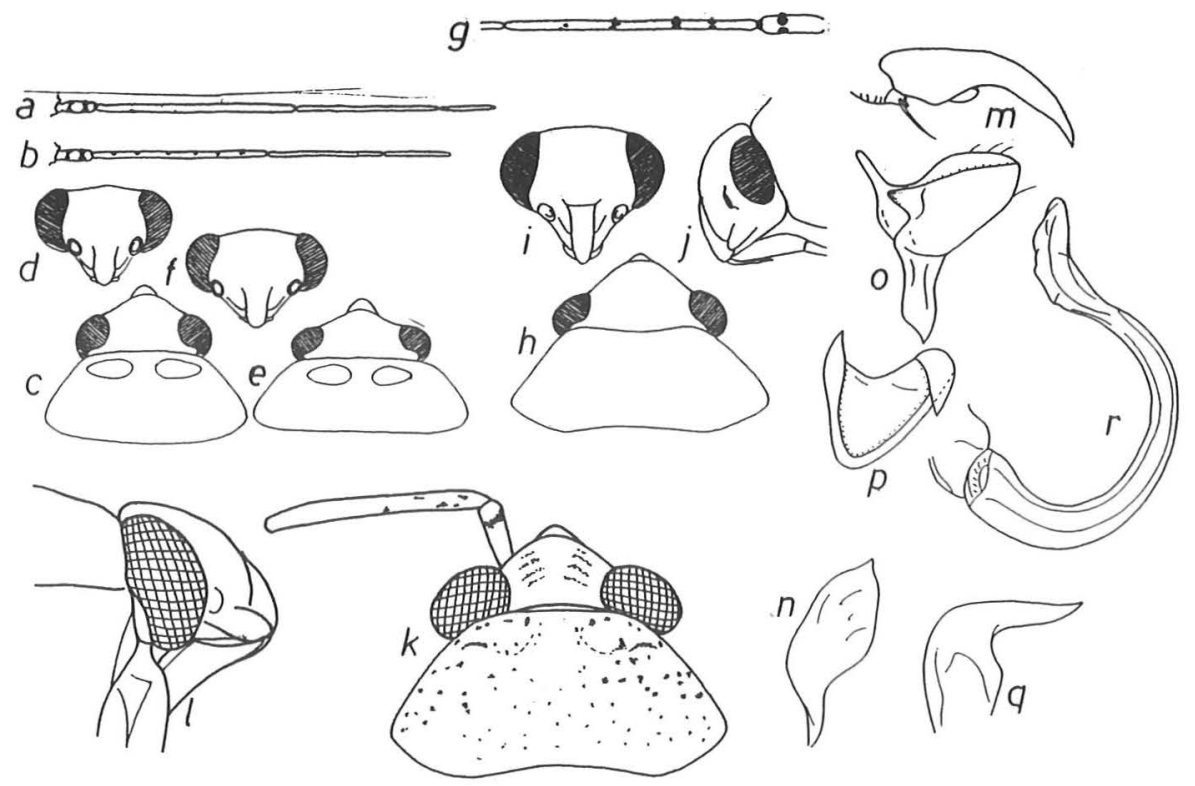

Fig. 1. Compsonannus puncticornis Reuter. a-b: male and female antenna; $c-f:$ male and female head and pronotum in dorsal view and head in apical view. $-C$. Iongicornis Wagner. g: male antenna; h: male head and pronotum, dorsal view; i-j: male head in apical and lateral view. - C. maculicornis (Linnavuori). k: male head and pronotum, dorsal view; l: male head, lateral view; m: claw; n: right style; o-p: left style; q: theca; r: vesica. - After Wagner 1971 and Linnavuori 1986.

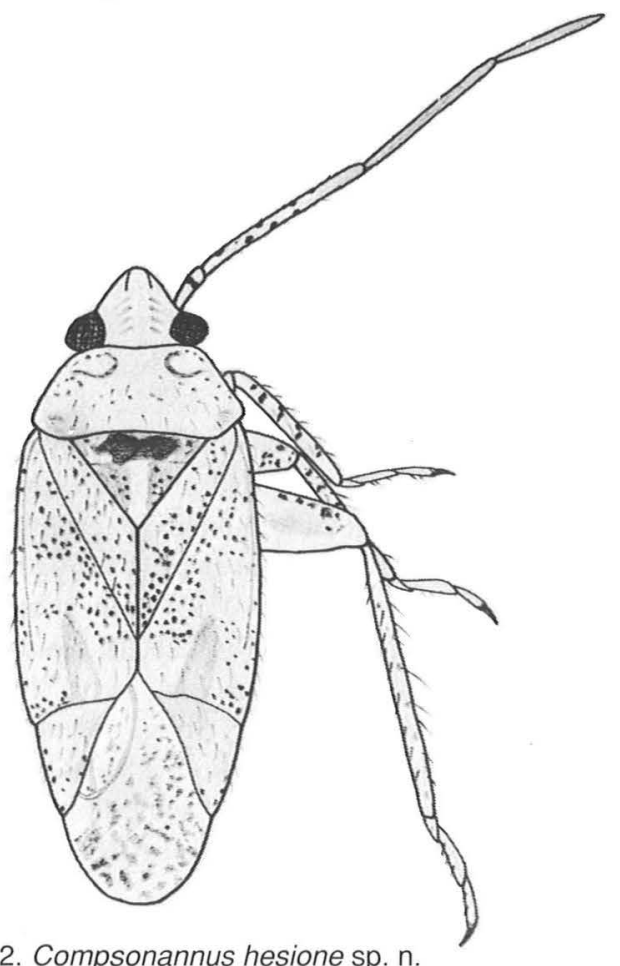

Fig. 2. Compsonannus hesione sp. $\mathrm{n}$.
C. maculicornis (Linnavuori), comb. $n$.

Figs. 1a-g, 3o

Compsidolon maculicorne Linnavuori 1986:171-173.

Types studied: Saudi Arabia, Hufuf, male holotype; 2 male paratypes, 8-23.IV.1978, Linnavuori, in coll. Linnavuori.

Material studied: Oman, $10^{7}$ without a locality label, in coll. Linnavuori.

Diagnosis: Like C. ovatus, but scutellum and elytra with distinct fuscous dotting. Vesica without apical process.

Length $3.0 \mathrm{~mm}$. Opaque. Whitish. Frons with faint fulvous lateral arcs. Eyes reddish gray. Antennae whitish ochraceous, 1st joint with transverse fuscous subapical spot on upper surface, 2nd with minute fuscous spots, $3 \mathrm{rd}$ and 4 th joints slightly embrowned. Pronotum with calli a little infumed, anterior margin in front of calli with a few dark brown spots, lateral margins behind calli 


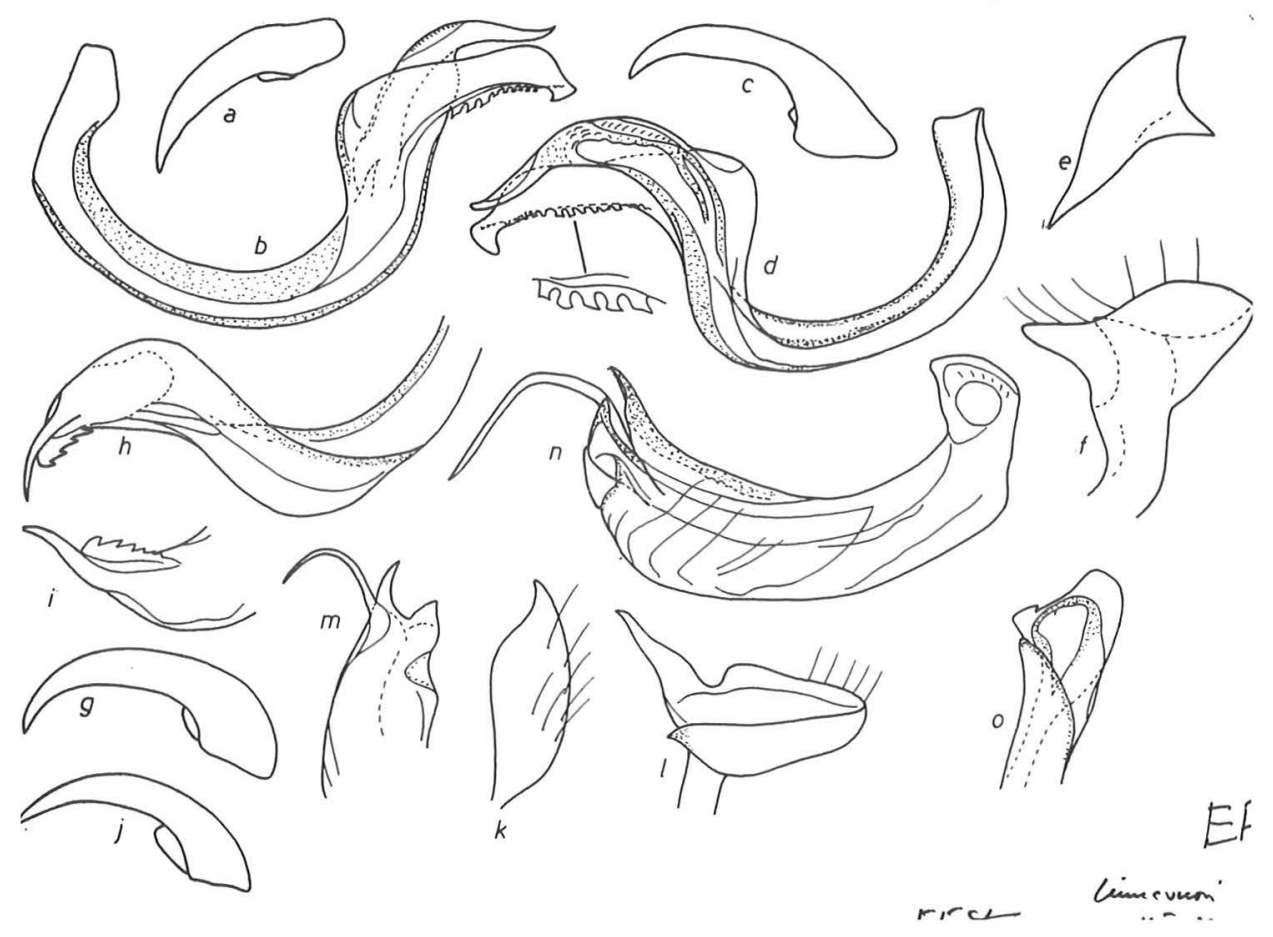

Fig. 3. Compsonannus puncticornis Reuter (holotype of thymelaeae Wagner). a: claw; b: vesica. - C. ovatus Wagner. c: claw; d: vesica; e: theca; f: left style. - C. longicornis Wagner. g: claw; h: vesica (of the holotype); $\mathrm{i}$ : apex of vesica (ex from 'Ein 'Avdat). - C. hesione sp. n. j: claw; k: right style; l: left style; n-m: vesica. - $C$. maculicornis (Linnavuori). o: apex of vesica in broad aspect.

with minute fuscous dots, disk otherwise with very faint light brown spots. Base of scutellum yellow with dense fuscous dotting, apex whitish, basally immaculate, apically ornamented with minute fuscous dots. Clavus with numerous fuscous dots; corium likewise with abundant fuscous spotting, extreme base immaculate, mesocorium with indistinctly dotted subapical area, dots on apical margin of corium small and relatively faint, apical part of M pink; cuneus with faint pink dots, lateral margin with a few, median margin with numerous fuscous dots; membrane milky with abundant fuscous irroration, veins fulvous. Under surface with fuscous markings, sides of thorax with a few fuscous dots. Legs whitish. Apices of fore and middle femora with a few dark dots, apical half of hind femur with abundant and confluent fuscous mottling; tibiae with distinct fuscous spots, spines pale.
Body $2.6 \times$ as long as broad at base of pronotum. Upper surface with longish semierect yellowish hairs and adpressed silvery tomentum. Head $0.7 \times$ as broad as basal width of pronotum, short; eyes large, ocular index 1.5. Proportions between antennal joints $15: 50: 36: 24,2$ nd joint $1.02 \times$ as long as diatone, $0.71 \times$ as long as basal width of pronotum. Rostrum extending slightly beyond hind coxae. Pronotum $2.5 \times$ as broad as long in middle. Proportions between hind tarsomeres 9:12:14.

Male genitalia in Figs. 1n-r, 3o.

Distribution: Eastern parts of the Arabian Peninsula.

Species of incertae sedis:

Atomoscelis antennalis Lindberg 1958 (described from the Cape Verde Islands), which was in- 
cluded in Compsonannus by Wagner, differs strikingly from the other species (head short and broad, basal margin of vertex distinctly keeled; 2nd antennal joint black with two pale rings; upper surface without dark dots; erect hairs on upper surface black; membrane without dark mottling; hind tibia with large black spots, tibial spines black) and is not congeneric with them. Its generic position will be treated elsewhere.

Acknowledgements. I am greatly indebted to Dr. A. Jansson and Prof. H. Strümpel for allowing me to examine type material preserved in the Helsinki and Hamburg Museums.

\section{Erratum}

Disney, R. H. L. 1990: Two new species and a revised key to Rhynchomicropteron (Diptera, Phoridae). - Entomol. Fennica 1:21-24.

Disney, R. H. L. 1990: A striking new species of Megaselia (Diptera, Phoridae) from Sulawesi, with re-evaluation of related genera. - Entomol. Fennica 1:25-31.

\section{References}

Lindberg, H. 1958: Hemiptera Insularum Caboverdensium. - Comment. Biol. 19(1):1-246.

Linnavuori, R. E. 1986: Heteroptera of Saudi Arabia. Fauna of Saudi Arabia 8:31-197.

Reuter, O. M. 1902: Capsidae novae mediterraneae IV. Öfv. Finska Vet. Soc. Förhandl. 44:51-70.

Wagner, E. 1965: Die Gattung Atomoscelis, Reuter und ihre Verwandten in der Paläarktis (Hem. Het. Miridae). Notulae Entomol. 45:74-92.

- 1968: Über einige Miriden aus Marokko (Heteroptera). - Notulae Entomol. 48:103-125

- 1971: Die Gattung Compsonannus Reuter, 1902 (Heteroptera, Miridae). - Notulae Entomol. 51:95-98.

- 1974: Compsonannus ovatus sp. n. (Heteroptera, Miridae). - Deutsche Entomol. Zeitsch. 21:165-166.

Received 4.V.1989

Disney, R. H. L. 1990: A key to Diplonevra males of the Australasian and Oriental Regions, including two new species (Diptera, Phoridae). - Entomol. Fennica 1:33-39.

Pages 22, 26, 34-37: For \# read o7 For a read o 